\title{
Left ventricular endomyocardial biopsy guided by intracardiac echocardiography via a trans- septal approach
}

\author{
Yasuhiro Yokoyama 다 , Kenichiro Yamagata 다, Hideaki Kanzaki, Kengo Kusano
}

Department of Cardiovascular Medicine, National Cerebral and Cardiovascular Center, Suita, Osaka, Japan

\section{Correspondence to} Dr Kenichiro Yamagata; look.tky@ncvc.go.jp

Accepted 8 June 2021

\section{DESCRIPTION}

A 29-year-old woman was referred to our hospital for catheter ablation (CA) due to symptomatic atrial fibrillation (AF), after two failed CA attempts at another hospital. She had presented with left ventricular dysfunction at the age of 1 year, with a suspected diagnosis of endocardial fibroelastosis (EFE) based on the high echo brightness of the endocardium. She had subsequently undergone endomyocardial biopsy (EMB) of the right ventricle at the age of 18 years, with no histopathological evidence of EFE. Biopsy of the left ventricular myocardium, which was not possible at the previous hospital, was indicated to determine the need for heart transplantation. We planned to perform the biopsy during the CA procedure.

Transthoracic echocardiography revealed a left ventricular spherical dilation and wall motion
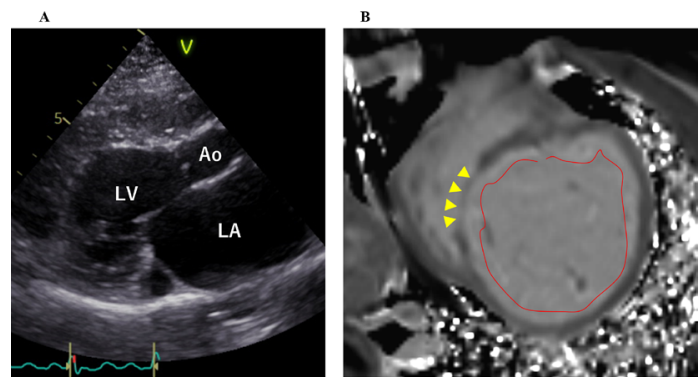

Figure 1 (A) Transthoracic echocardiography showing spherical dilation and wall motion abnormality (long axis view). (B) Cardiac MRI showing thinning of the inferoseptal aspect of the left ventricle (small arrows) and an increased extracellular volume fraction (red lines). Ao, aorta; LA, left atrium; LV, left ventricle.

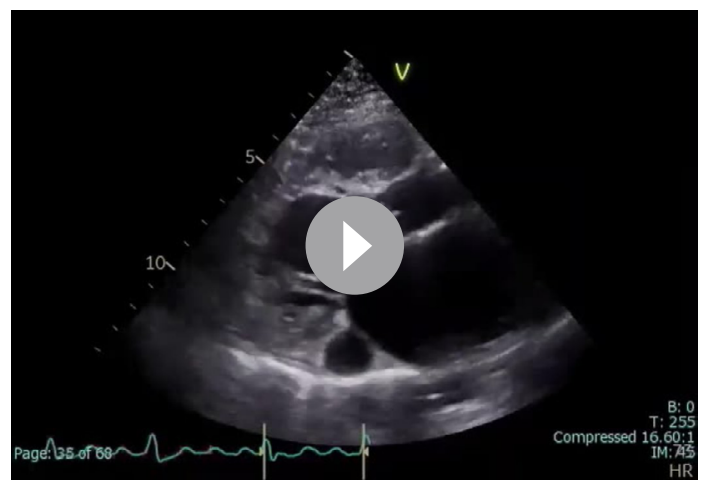

Video 1 Transthoracic echocardiographic long axis views.
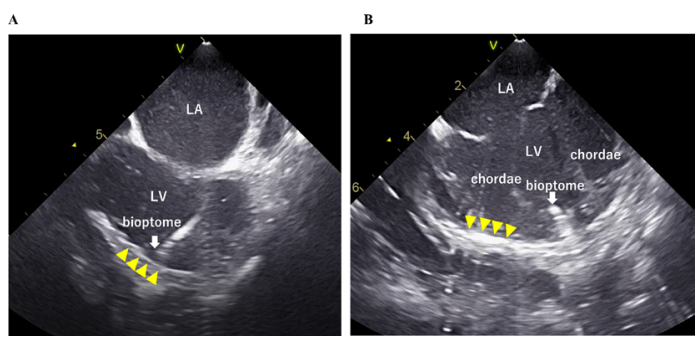

Figure 2 Intracardiac echocardiography images obtained during the procedure. (A) The tip of the bioptome is shown next to the high echoic area of the thinned inferoseptal aspect of the left ventricle where repeated biopsy attempts failed (small arrowhead). (B) The chordae tendineae were visualised and the bioptome manipulated to avoid injury, with subsequent advancement to the mid-posterior wall where endomyocardial biopsy was performed. LA, left atrium; LV, left ventricle.

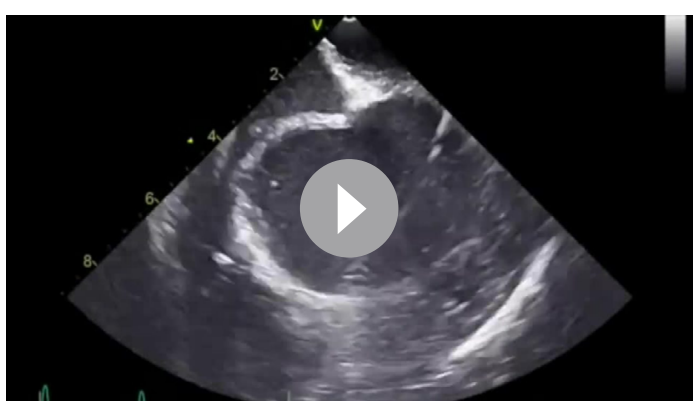

Video 2 The bioptome was slipped at the high echoic thin lesion (intracardiac echocardiography images).

abnormality (figure 1A, video 1). Cardiac MRI revealed a thinning of the inferoseptal aspect of the left ventricle, with an increased extracellular volume fraction (figure 1B). Heart palpitation during AF negatively impacted her quality of life. Her heart failure status was associated with left ventricular dysfunction, although without evidence of pathological EFE findings. After careful consideration, we decided to perform, sequentially, left ventricular EMB for histopathological diagnosis and $\mathrm{CA}$ for $\mathrm{AF}$, under general anaesthesia.

After trans-septal puncture, via the femoral vein, an 8-Fr intracardiac echocardiograph (ICE) (SOUNDSTAR, Biosense Webster, Diamond Bar, California) and an 8.5-Fr deflectable sheath (Agilis Sheath, St. Jude Medical, St.-Paul, Minnesota) were placed in the left atrium. To approach the left ventricle, the trans-septal puncture was performed 


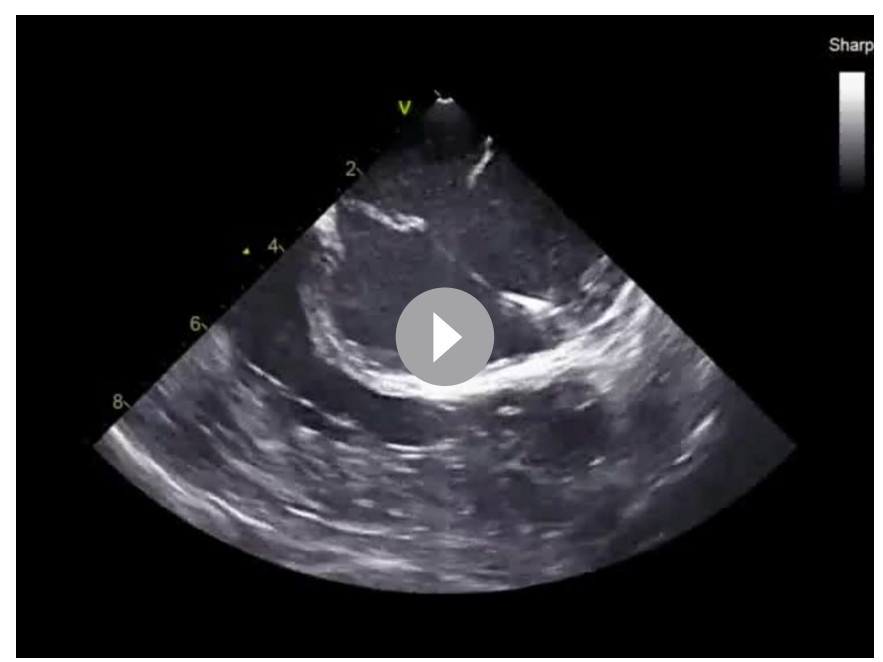

Video 3 The endomyocardial biopsy was successfully performed (intracardiac echocardiography images).

at the point where the left atrial appendage could be observed in the ICE image. Under ICE guidance, the deflectable sheath was bent and aimed to the middle of the mitral valve annulus. Thereafter, the bioptome was inserted into the left ventricle and directed to the high echoic lesion in the thinned region of the inferoseptal wall of the left ventricle. However, specimens could not be obtained from the site of the lesion due to slippage of the bioptome (figure $2 \mathrm{~A}$, video 2 ). The bioptome was then advanced to the mid-posterior wall of the left ventricle where EMB was successfully performed, with two specimens obtained for diagnostic purposes (figure $2 \mathrm{~B}$, video 3 ), The total EMB procedure time was $14 \mathrm{~min}$ and the dose area product was $95.1 \mathrm{mGy} \cdot \mathrm{cm}^{2}$. After EMB, CA was performed without complication, including no mitral valve regurgitation, and the sinus rhythm was restored.

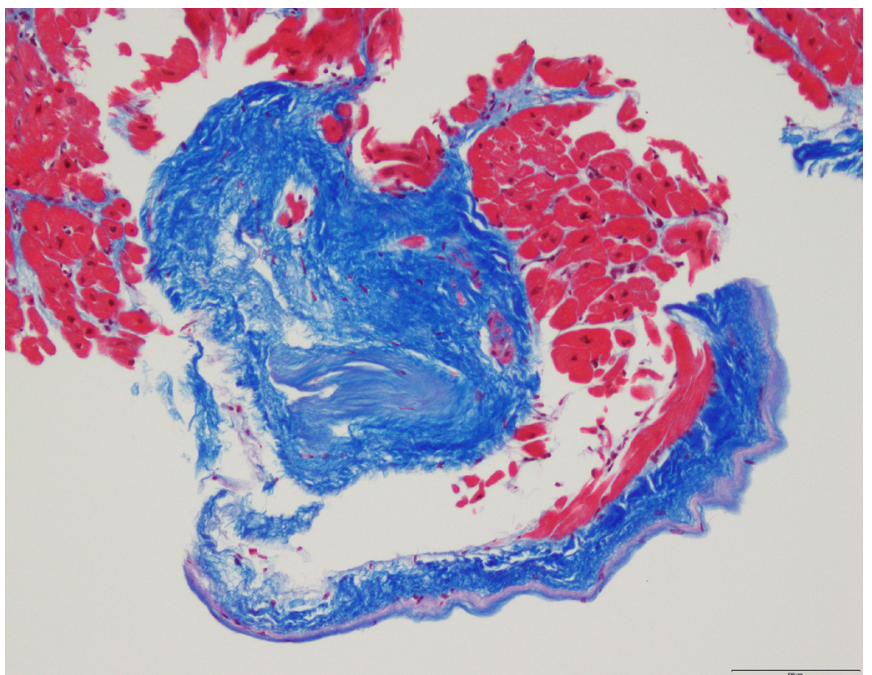

Figure 3 Pathological examination confirming endocardial fibrous thickening and interstitial fibrosis of the left ventricle (Masson's trichrome stain). Scale bar, $100 \mu \mathrm{m}$.

\section{Patient's perspective}

I feel better after termination of the arrhythmias. It is important for me to diagnose with safety and accuracy.

Learning points

- Intracardiac echocardiograph guidance allows us to navigate the bioptome to the ideal location.

- This method could improve the rate of success of diagnostic biopsy for cardiomyopathies.

- This technique could permit left ventricular biopsy when the transaortic approach is difficult, such as after aortic valve replacement or arterial vascular access problems.

Pathological examination of the specimens revealed an endocardial fibrous thickening and interstitial fibrosis of the left ventricle (figure 3). These findings were not observed in the previous specimens from the right ventricle and were indicative of secondary EFE.

The overall complication rate for EMB is low, at $1 \%-2 \%$ for experienced surgeons. ${ }^{1}$ However, when complications do occur, such as cardiac perforation or valve regurgitation, these are occasionally lethal, especially in patients with previous heart disease. ICE-guided EMB has a potential to reduce EMB-related complication as it enables direct visualisation of the bioptome to avoid performing a biopsy from critical locations. Notably, sampling errors do occur frequently in cases with a localised lesion, such as cardiac sarcoidosis. ${ }^{2}$ ICE guidance for EMB can be helpful in this regard, with previous studies having described its benefit for EMB from the right atrium and ventricle. ${ }^{34}$ To our knowledge, this is the first report of ICE-guided EMB from the left ventricle, via a trans-septal approach.

Contributors $Y Y, K Y$ and $K F K$ wrote the manuscript. $Y Y, K Y$ and $H K$ perfomed this procedure.

Funding The authors have not declared a specific grant for this research from any funding agency in the public, commercial or not-for-profit sectors.

Competing interests None declared.

Patient consent for publication Not required.

Provenance and peer review Not commissioned; externally peer reviewed.

\section{ORCID iDs}

Yasuhiro Yokoyama http://orcid.org/0000-0001-9307-0486

Kenichiro Yamagata http://orcid.org/0000-0002-9571-7017

\section{REFERENCES}

1 Leone O, Veinot JP, Angelini A, et al. 2011 consensus statement on endomyocardia biopsy from the association for European cardiovascular pathology and the Society for cardiovascular pathology. Cardiovasc Pathol 2012;21:245-74.

2 Uemura A, Morimoto S, Hiramitsu S, et al. Histologic diagnostic rate of cardiac sarcoidosis: evaluation of endomyocardial biopsies. Am Heart J 1999;138:299-302.

3 Takashima A, Ogata T, Yamada H, et al. Intracardiac Echocardiography-Guided biopsy of a lipomatous cardiac tumor arising from the interatrial septum. Circ J 2017:81:1553-5

4 Zanobini M, Dello Russo A, Saccocci M. Endomyocardial biopsy guided by intracardiac echocardiography as a key step in intracardiac mass diagnosis. BMC Cardiovasc Disord 2018;18:15. 
Copyright 2021 BMJ Publishing Group. All rights reserved. For permission to reuse any of this content visit https://www.bmj.com/company/products-services/rights-and-licensing/permissions/

BMJ Case Report Fellows may re-use this article for personal use and teaching without any further permission.

Become a Fellow of BMJ Case Reports today and you can:

- Submit as many cases as you like

- Enjoy fast sympathetic peer review and rapid publication of accepted articles

Access all the published articles

Re-use any of the published material for personal use and teaching without further permission

Customer Service

If you have any further queries about your subscription, please contact our customer services team on +44 (0) 2071111105 or via email at support@bmj.com.

Visit casereports.bmj.com for more articles like this and to become a Fellow 